\title{
Determination of the Penetration Level of ASVT Sub-stations on 132kv Line Without Voltage Profile Violation
}

\author{
Kitheka Joel Mwithui $^{1}$, Michael Juma Saulo ${ }^{2}$, David Murage ${ }^{3}$ \\ ${ }^{1}$ Jomo Kenyatta University of Agriculture and Technology, Nairobi, Kenya \\ ${ }^{2}$ Department of Electrical and Electronic Engineering/Faculty of Engineering and Technology, Technical University of Mombasa, Mombasa, \\ Kenya \\ ${ }^{3}$ Department of Electrical and Electronic Engineering, Jomo Kenyatta University of Agriculture and Technology, Nairobi, Kenya
}

Email address:

kithekajoelmwithui@tum.ac.ke (K. J. Mwithui), michaelsaulo@tum.ac.ke (M. J. Saulo), dkmurage25@yahoo.com (D. Murage)

\section{To cite this article:}

Kitheka Joel Mwithui, Michael Juma Saulo, David Murage. Determination of the Penetration Level of ASVT Sub-stations on 132kv Line Without Voltage Profile Violation. International Journal of Energy and Power Engineering. Vol. 5, No. 1, 2016, pp. $22-28$.

doi: $10.11648 /$ j.ijepe.20160501.14

\begin{abstract}
In developing countries, there are many high voltage transmission lines which transverse villages not supplied with electricity to supply main towns and industrial areas. The conventional substations are too expensive and the power distributor can only set them up if return on investment is assured. Non-conventional (ASVT) sub-stations have been tried and found to be technically successful in stepping down $132 \mathrm{kv}$ to low voltages like 240 volts in one step to supply single phase loads. Though this technology is cheap and technically fit to be applied in areas of low demand were setting up conventional sub-station will be uneconomical, the technology is not fast spreading in Sub-Sahara Africa (SSA) where there are well established transmission line but poor distribution network. More so the technology remains as a pilot project in countries like Congo were they were first tried. This research aimed at investigating whether violation of voltage profile of the transmission line could have led to low spread of ASVT sub-station technology in Sub-Sahara Africa. The investigation of the maximum number of ASVT substations which could be terminated on $132 \mathrm{kv}$ line to supply these villages with electricity without voltage profile violation was carried out. In this research, transmission line and ASVT substation models were implemented using SIMULINK software in MATLAB environment. Surge impedance curves were also used to identify the point of voltage instability or voltage collapse in the system.
\end{abstract}

Keywords: Auxiliary Service Voltage Transformer (ASVT), Voltage Profile (VP), Transmission Line (TL), Penetration Level (PL)

\section{Introduction}

In most Sub-Sahara Africa rural areas, the concentration of electricity users is low and the cost of deploying a conventional sub-station is very high. As a result power utility cannot be able to generate an adequate return on investment necessary to bring a conventional distribution sub-station on line $[1,2]$, on the other hand there are large numbers of rural communities in these areas living around or in close proximity to high transmission lines but are not supplied with electricity. The main obstacle is that these transmission lines have very high voltages that cannot be directly and cheaply be used for electrification $[3,4,10]$.

To address the prohibitive costs incurred with the use of conventional sub-stations, non conventional substation namely; Auxiliary Service Voltage transformer (ASVT) sub- station is explored in this journal.

The auxiliary service voltage transformer also known as station service voltage transformer (SSVT) combines the characteristics of instrument transformer with power distribution capability. In this transformer, the high voltage side is connected directly to the overhead transmission line of either $220 \mathrm{kV}$ or $132 \mathrm{kV}$, while the secondary side may be of typical voltage ratings of $240 \mathrm{~V}, 480 \mathrm{~V}, 600 \mathrm{~V}$ or any other voltage level supplies designed on order. One step down principle is applied to achieve the low voltages just like in instrument transformers [5].

The Auxiliary service voltage transformer can either be used with its low voltage output to directly supply needed power near transmission lines or simply step up the ASVT low voltage output through distribution transformer for a local distribution network. 
In developing countries where transmission line infrastructure is already in place but a wide spread distribution infrastructure is lacking, the non conventional distribution sub-station technologies can be used to greatly reduce the electrification costs for small villages $[6,9]$.

\section{The Auxiliary Service Voltage Transformer}

The ASVT, sometimes known as a station service voltage transformer (SSVT) is insulated in sulfur hexafluoride (SF6) gas and combines the characteristics of instrument transformer with power distribution capability [3, 5, 7]. All the dielectric characteristic of the conventional instrument transformer are applicable to ASVT even though these are hybrid apparatus which are between an instrument transformer and a distribution transformer. These transformers fulfill the standards for both types, i.e. IEEEC 57.13.1993 and IEEE C57.12.00 [8]. This inductive transformer has a very high thermal power in comparison with conventional instrument transformer, in general from 20 up to 60 times more than the design of new generation, without reaching the capacity of a power transformer. [8]

The ASVT allows directly connection from high voltage line and transforms voltage from $230 \mathrm{kV}$ to $600 \mathrm{~V}$ or even smaller in one step, with a thermal power of $50 \mathrm{kVA}$ up to 330kVA per phase $[1,3,6]$.

ASVTs were originally designed to suit supply for auxiliary services within the substation such as lighting loads, motor loads and instrument purposes [4, 8]. In developing countries where transmission lines infrastructure is already in place but a wide spread distribution infrastructure is lacking, the non conventional ASVT substation technologies can be used as a compact transformer to greatly reduce the electrification cost for rural electrification. The ASVT can be used to supply loads directly with its low voltage or simply step up the ASVT low voltage output through distribution transformer for local distribution network.

Tapping the high voltage transmission line and connecting an ASVT with a small foot print sub-station will provide affordable, readily available electricity to many rural dwellers in close proximity to high voltage lines and presently without power $[4,6]$.

\section{Conventional Sub-stations}

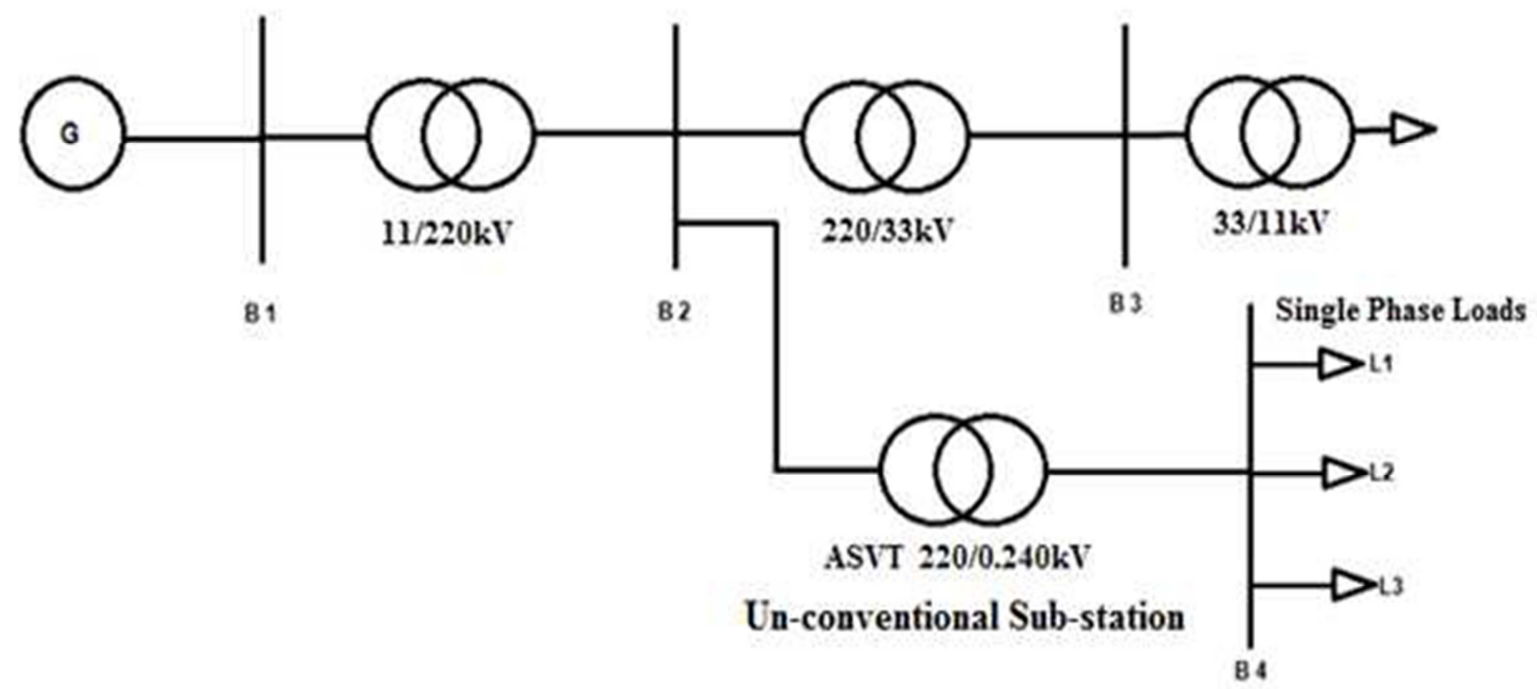

Fig. 1. ASVT VS Conventional Sub-station.

\section{Methodology}

\subsection{Penetration Level of ASVT Substations}

This research was aimed at determining the maximum number of substations that can be terminated on a $440 \mathrm{KM}$, $132 \mathrm{kv}$ transmission line to supply power to the villages without violating the voltage profile of the transmission line.

To carry out the simulation, SIMULINK software in a MATLAB environment was used. The transmission line parameters used were calculated as shown below.

The ASVT substations were terminated on the transmission line from the generation point till the voltage profile of the network was violated. The maximum numbers of ASVT substations terminated were noted.

\subsection{Transmission Line Parameters}

(a). Inductance of a transmission line,

$$
\mathrm{L}=4 \times 10^{-7} \operatorname{In} \frac{D}{r^{\prime}}
$$

Where

$$
r^{\prime}=0.7788 \mathrm{r}
$$

$\mathrm{D}=$ distance between conductors ( 1 metres)

$\mathrm{R}=$ radius of each conductor ( 0.03 metres)

$$
\mathrm{L}=4 \times 10^{-7} \ln \frac{D}{0.7788(0.03)}=1.5 \times 10^{-6} \mathrm{H} / \mathrm{M}
$$

$\mathrm{L}=1.5 \mathrm{mH} / \mathrm{KM}$

(b). Resistance of the transmission line 


$$
\begin{gathered}
\mathrm{R}=\frac{\varrho L}{A}, \mathrm{~A}=\pi r^{2}=\pi(0.03)^{2}=2.827 \times 10^{-3} \mathrm{~m}^{2} \\
\mathrm{R}=\frac{2.83 \times 10^{-8}}{2.83 \times 10^{-3}} \times 1000 \mathrm{~m}=0.01 \Omega / \mathrm{KM}
\end{gathered}
$$

(c). Capacitance of transmission line

$$
\mathrm{C}=\frac{2 \pi}{\ln \frac{D}{r}}
$$

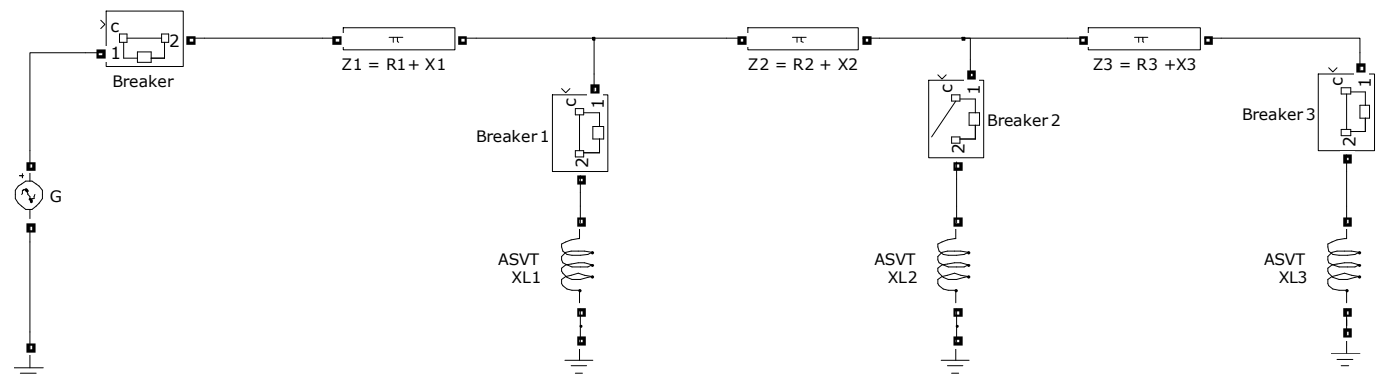

Fig. 2. ASVT termination on a transmission line.

Considering breaker 3 alone to be closed, with 1 and 2 open, the impedance of the transmission line shall appear as follows: [11]

$$
Z_{l}=R_{l}+X_{l}
$$

Where $Z_{l}$ is the total impedance of the transmission line

$$
\begin{gathered}
R_{l}=R_{1}+R_{2}+R_{3} \\
X_{l}=X_{1}+X_{2}+X_{3}+X l_{3}
\end{gathered}
$$

Considering breaker 3 and breaker 1 to be closed;

The output reactance $\left(x_{o}\right)=\left(X_{2}+X_{3}+X l_{3}\right) / /\left(X l_{1}\right)$

If $X_{1}=X_{2}=X_{3}$ and $X l_{1}=X l_{2}=X l_{3}$ then expression (3) can be reduced to:

$$
\left(2 X_{1}+X l_{1}\right) / /\left(X l_{1}\right) \cong X l_{1}
$$

While the input reactance

$$
\left(x_{i}\right)=X_{1}
$$

In a transmission conductor, the resistance of the line is supposed to be very small to reduce power losses i.e. $\mathrm{p}=I^{2} R$ watts. Thus resistance can be considered negligible. This means in this case equivalent reactance of the line will be given by:

$$
\begin{gathered}
\mathrm{C}=\frac{2 \pi 8.85 \times 10^{-12}}{\ln \frac{1}{0.03}} \\
\mathrm{C}=1.586 \times 10^{-8} \mathrm{~F} / \mathrm{KM}
\end{gathered}
$$

\subsection{Termination of Reactive Components on a Transmission Line}




\subsection{ASVT Substations Terminated on $132 \mathrm{kv}$ Transmission Line}

This research was carried out to investigate the maximum number of ASVT sub-stations that can be terminated on a $440 \mathrm{KM}, 132 \mathrm{kv}$ transmission line to supply villages living within a radius of 500metres without violating the voltage profile of the line. The transmission line model shown in Fig 3 was constructed in SIMULINK software using MATLAB environment. The ASVT sub-stations were terminated to the transmission line network via a circuit breaker. To monitor the changes of the voltage profile of the network on terminating sub-stations, ammeter, voltmeters and oscilloscopes were used.

\subsection{Voltage Stability Limit}

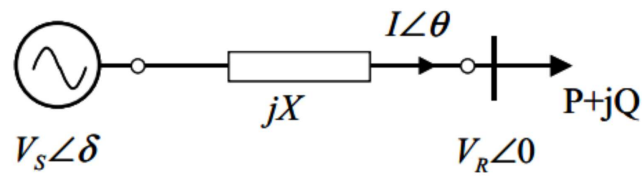

Fig. 4. Single line diagram for voltage stability limit.

Where; [16]

$$
\begin{gathered}
\mathrm{P}=\frac{V_{R V_{S}}}{X} \sin \theta \\
\mathrm{Q}=\frac{V_{R V_{S}}}{X} \sin \theta-\frac{\left(V_{R}\right)^{2}}{X}
\end{gathered}
$$

At the receiving end,

$$
V_{R} I^{*}=\mathrm{P}+\mathrm{jQ}
$$

Power delivered to the load as a function of the receiving end voltage when $\mathrm{Q}=0$ is given by $\mathrm{p}=\sqrt{\frac{\left(v_{S}\right)-\left(v_{R}\right)}{X}} V_{R}$

The maximum power is attained when $\frac{d_{p}}{d_{V R}}=0$

$P_{\max }=\frac{V_{S}{ }^{2}}{2 x}$, this is the voltage transmission limit of the power transmission line. Where; $V_{\text {nose }}=\frac{V_{S}}{\sqrt{2}}$

The transmission capacity of a particular line is limited by its thermal capacity. However, in case of long high voltage AC lines efficiency of transmission capacity is below its thermal limit and restricted by angular and voltage stability limits which restricts line load ability up to its Surge Impedance Loading (SIL) level. [15]

\subsection{Results and Discussion}

The research was carried out by considering a transmission line of $440 \mathrm{KM}$ and the calculated transmission parameters used were $\mathrm{L}=1.5 \mathrm{mH} / \mathrm{KM}, \mathrm{C}=158.6 \mu \mathrm{F} / \mathrm{KM}, \mathrm{R}=0.01 \Omega / \mathrm{KM}$.

The number of ASVT terminated on the high voltage transmission line was varied to monitor the number of ASVT sub-stations that can be terminated on a transmission line without violating the voltage profile. Table 1 displays the steady state voltage of the transmission line. Voltage wave forms were also displayed and used to monitor the response of voltage levels with variation of the number of ASVTs terminated.

Table 1. Voltages levels vs pi-section distance with 3 ASVT, 7ASVT, 9ASVT \& 10ASVT sub-stations terminated.

\begin{tabular}{llll}
\hline $\begin{array}{l}\text { Length of HV line from } \\
\text { generation station(KM) }\end{array}$ & $\begin{array}{l}\text { Voltmeter reading (V), } \\
\text { 3ASVT terminated }\end{array}$ & $\begin{array}{l}\text { Voltmeter reading (V), } \\
\text { 7ASVT terminated }\end{array}$ & $\begin{array}{l}\text { Voltmeter reading (V), } \\
\text { 9ASVT terminated }\end{array}$ \\
\hline 62.857 & 133363.67 & 133353.73 & $\begin{array}{l}\text { Voltmeter reading (V), } \\
\text { 10ASVT terminated }\end{array}$ \\
125.714 & 134522.34 & 134502.14 & 134007.87 \\
188.571 & 135474.26 & 135444.50 & 134826.18 \\
251.428 & 136217.95 & 136178.36 & 135519.70 \\
314.285 & 136749.90 & 136702.91 & 136087.78 \\
377.142 & 137069.00 & 137017.00 & 136845.64 \\
391.12 & - & - & 137034.71 \\
440 & - & - & 137096.93 \\
\hline
\end{tabular}

The transmission line voltage profile was to be maintained at $6 \%$ as per the Kenya power and lighting company recommendations. This means that the voltage levels were to be in the range $132000 \pm 7920$ Volts.

From table 1, the ASVT sub-stations were terminated at a pi-section of 62.857KM from each other and the ASVT substations terminated in the order of 3, 7, 9 and 10. The above results shows that the voltage profile of the $440 \mathrm{KM}, 132 \mathrm{kv}$ transmission line was maintained when $3 \mathrm{ASVT}$ sub-stations, 7ASVT sub-stations and 9ASVT sub-stations were terminated. On terminating the tenth ASVT sub-station, the voltage levels of the transmission line appears to have decreased drastically. This means a maximum of nine ASVT sub-stations can be used to supply villages living at a radius of 500metres with electricity without violating the voltage profile of a $440 \mathrm{KM}, 132 \mathrm{kv}$ transmission line.

The data captured in table 1was plotted on a graph for further analysis and the following results are as shown in Fig 5.

From Fig 5, it is clear that the voltage profile of the $440 \mathrm{KM}, 132 \mathrm{kv}$ network was maintained when up to nine ASVT sub-stations were terminated. The transmission line voltage levels changed drastically on terminating the tenth ASVT sub-station as shown by the blue line on the graph. This means the transmission line voltage profile was violated on terminating the tenth ASVT sub-station.

To further analyse the situation, the voltage waveforms of the transmission line and ASVT sub-stations were displayed before and after the voltage violation. 


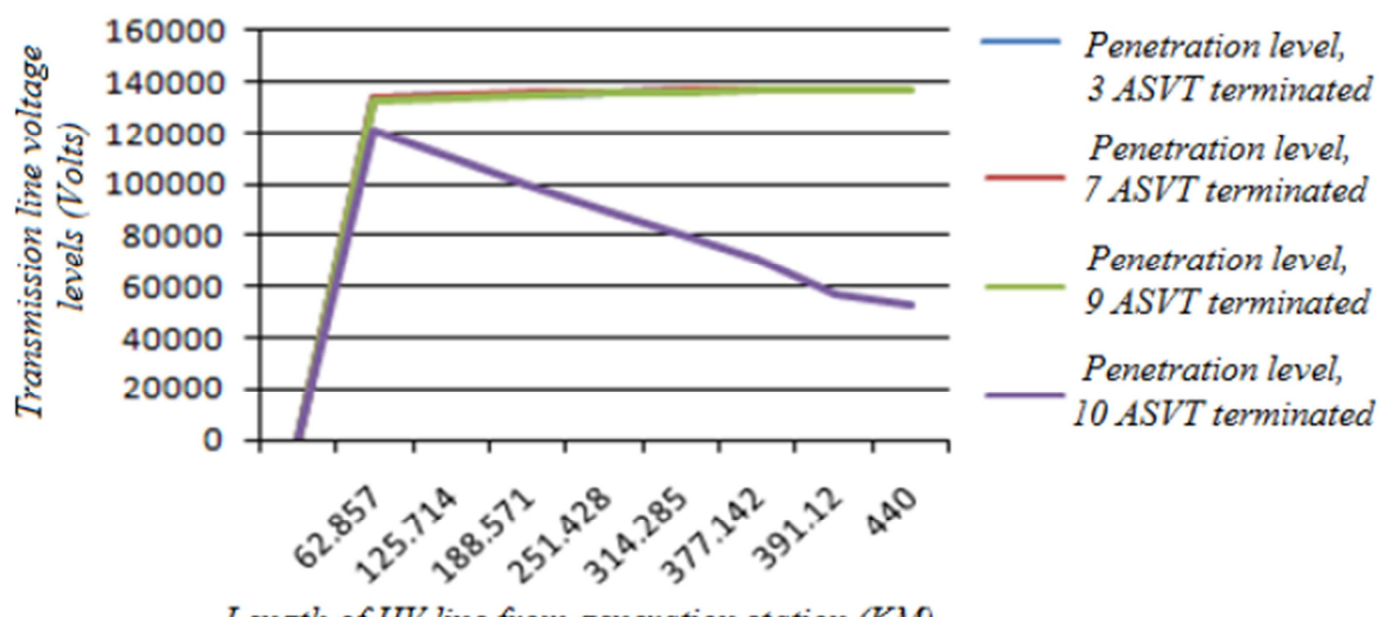

Length of $\mathrm{HV}$ line from generation station (KM)

Fig. 5. Penetration level graph.

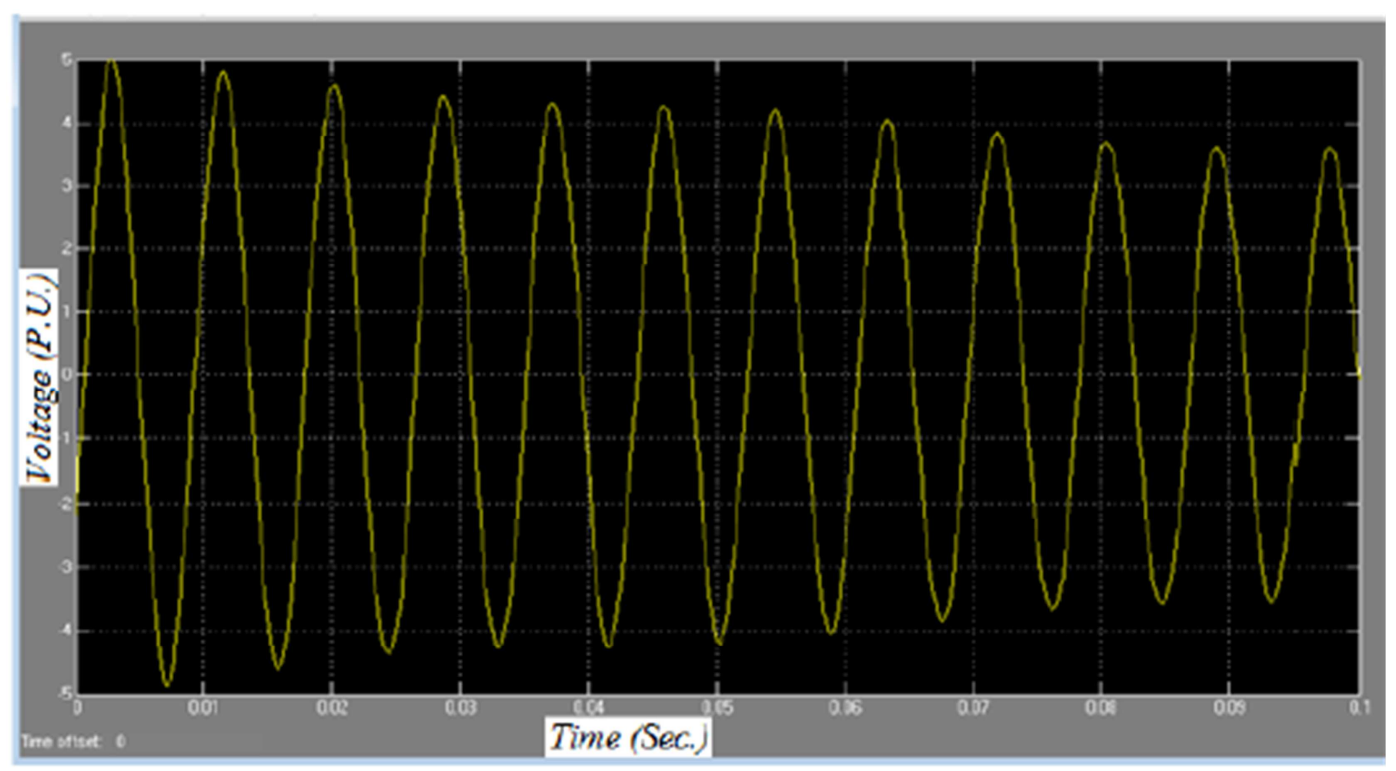

Fig. 6. Transmission line voltage waveform when maximum of nine ASVT sub-stations were terminated.

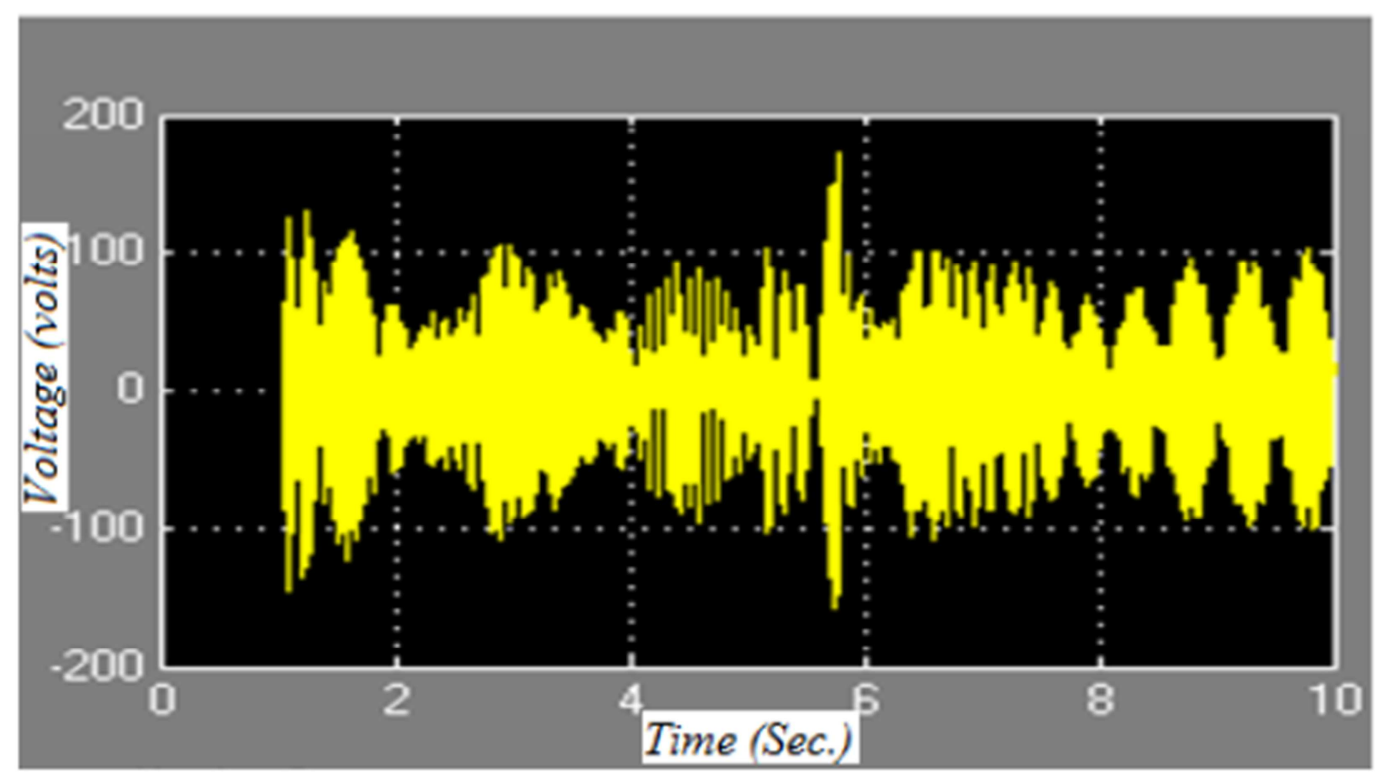

Fig. 7. Voltage waveform when ten ASVT sub-stations are terminated. 
When a maximum of ten ASVT sub-stations were terminated on the $440 \mathrm{KM}, 132 \mathrm{kv}$ transmission line network the line voltage waveform appeared as shown in Fig 7.

Fig 7: transmission line voltage waveform after ten ASVT sub-stations were terminated.

The change of the transmission line waveform when the tenth ASVT substation was terminated on the $440 \mathrm{KM}, 132 \mathrm{kv}$ transmission line was also noted.

This implied that the surge impedance loading of the transmission line had changed and could not contain an additional ASVT sub-station in the system. This led to voltage instability or voltage collapse.

Further investigations were carried out to display the output voltage waveforms of the ASVT sub-stations and results were as captured in fig 8 and 9.

From the study of Fig 8 and 9, it was observed that when the voltage profile of the $132 \mathrm{kv}$ transmission line was violated, the ASVT sub-station transmission line was also distorted. This implies that for the villages located 500metres from the transmission line to be supplied with electricty then the ASVT sub-stations terminated to the transmission line should not be more than nine.

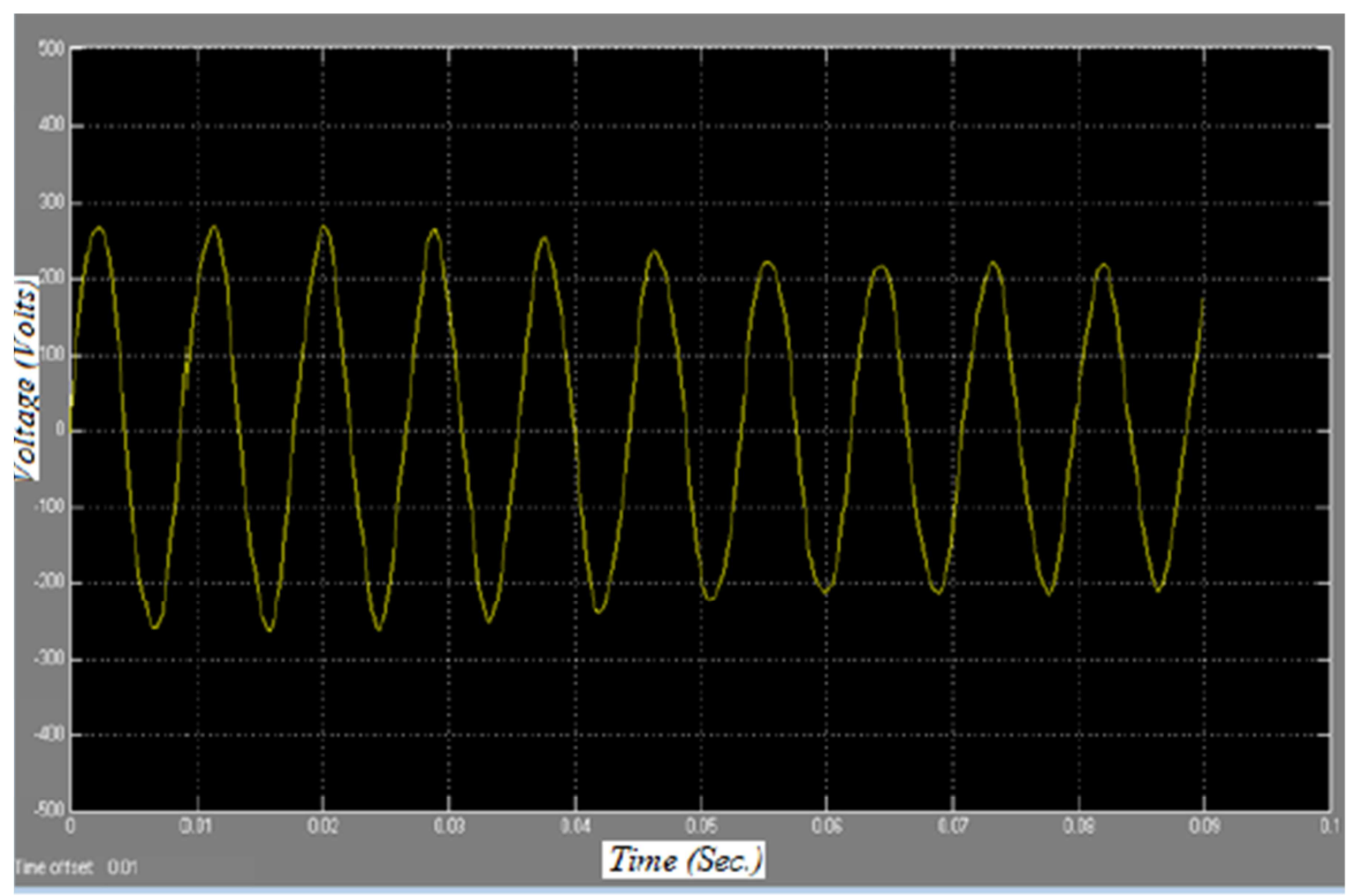

Fig. 8. ASVT sub-station output before violation of the line voltage profile.

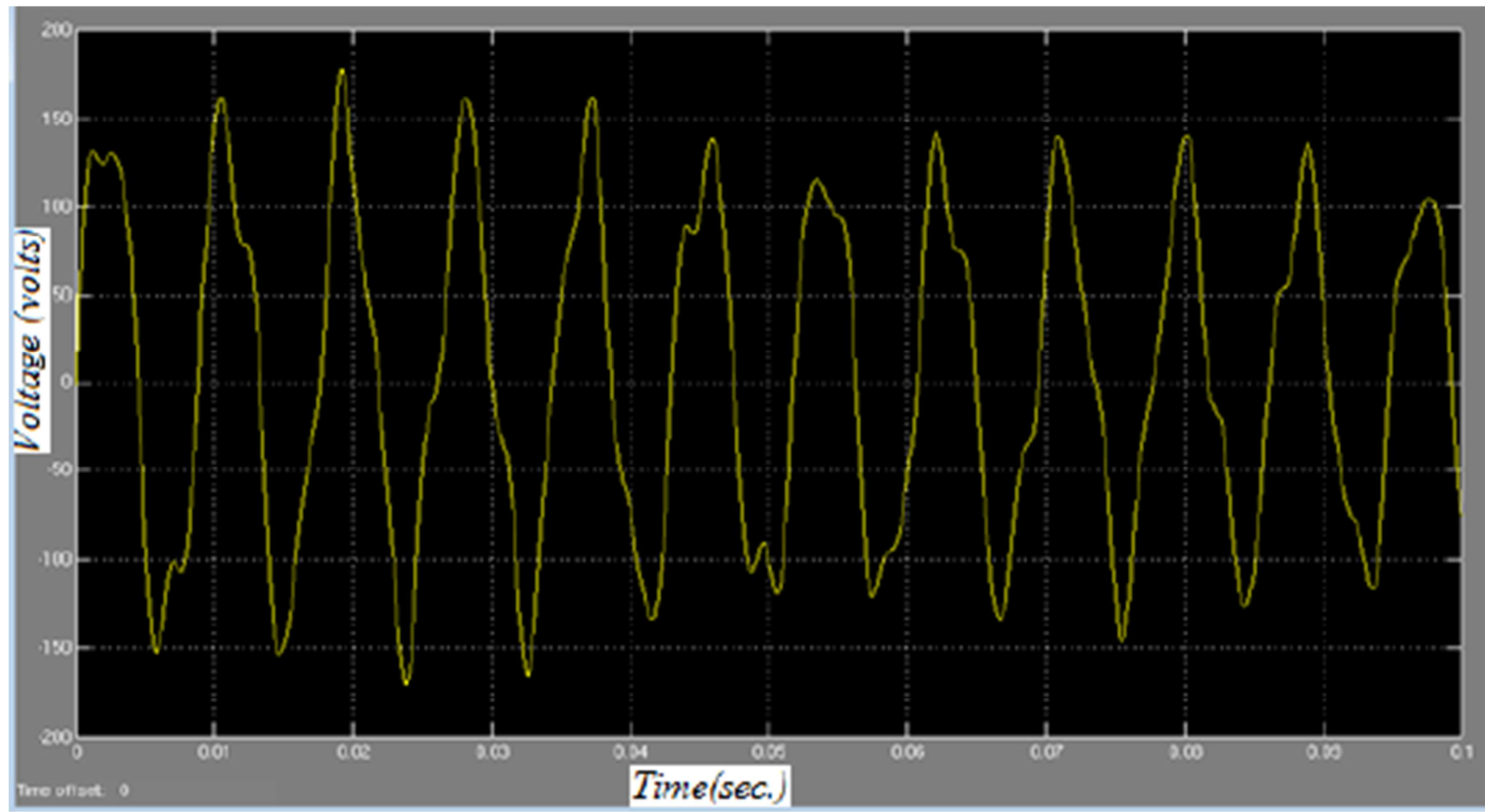

Fig. 9. ASVT sub-station output after violation of the line voltage profile. 


\subsection{Voltage Stability}

The $440 \mathrm{KM}, 132 \mathrm{kv}$ transimission voltage was investigated using surge impedance loading curve. The SIL curve was used to investigate the effect of violation of transmission line voltage profile to its voltage stability and the results are as depicted on fig 10.

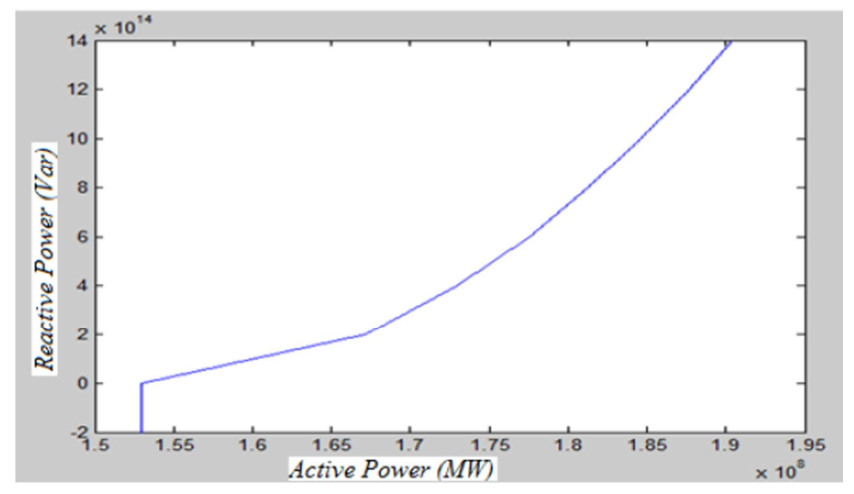

Fig. 10. SIL curve.

Fig 10 shows a surge impedance loading curve when the voltage profile of the network is maintained and when the profile is violated.

From $1.53 \times 10^{8}$ to $1.7 \times 10^{8} \mathrm{MW}$, the voltage stability of the network appears to be sound, beyond this point there is an exponential growth of the curve depicted system voltage instability which further led to a voltage collapse.

This resulted from the fact that further termination of the ASVT sub-station led to changes of the transmission line inductance and capacitance which brought forth changes in line impedance. These changes in line impedance interfered with the surge impedance loading of the transmission line resulting to voltage instability or vollage collapse.

\section{Conclusion}

A maximum of nine auxiliary service voltage transformer sub-stations can be used to supply villages living at close proximity to $440 \mathrm{KM}, 132 \mathrm{kv}$ transmission line without violating the voltage profile of the system.

\section{References}

[1] Saulo M. J, Gaunt C. T, and Mbogho M. S (2012): Comparative assessment of capacitor coupling substation and Auxiliary Service Voltage Transformer for Rural Electrification, $2^{\text {nd }}$ Annual Kabarak University, Nakuru, Kenya.
[2] Dagbjartsson G., Gaunt C. T, Zomers A. N: Rural Electrification, A scoping report.

[3] Gomez, R. G, Solano, A. S, Acosta, E. A (2010): Rural Electrification project development, using Auxiliary Transformers, location of Tubares, Chihuahua, Mexico.

[4] Saulo M. J, Gaunt C. T (2014) "implication of using Auxiliary Service Voltage Transformer substation for Rural Electrification." International journal of energy and power engineering. [on - line] 4(2-1) pp 1-11. Capetown, South Africa

[5] Arteche Instrument Transformer manual (2010): ASVT - 245 and ASVT -145 manual and technical brochures

[6] Anderson, G. O, Yanev K. (2010): Non convectional substation and distribution system for rural Electrification. $3^{\text {rd }}$ IASTED Africa PES 2010. Gaborone, Botswana.

[7] Omboua A. (2006) Application report "the high voltage line becomes a power distributor: A successful test in Congo Brazzaville" Congo.

[8] Omar C., Gomez R. Solano A. Acosta E. (2010) Eradicating energy poverty "Rural Electrification in Chuahuahua, Mexico at one third of the cost versus a conventional substation" Mexico.

[9] Michael J. S, Mbogho M. S (2014): Implication of capacitor coupling substation on Rural Electrification planning in Kenya. Proceedings of $3^{\text {rd }}$ international Kenya society of Electrical and Electronics Engineers conference, KSEEE 2014. Mombasa, Kenya.

[10] Haanyika C. M, (2008): Rural electrification in Zambia: A policy and institutional analysis: Energy policy 36 (2008) pp $1044-1058$.

[11] J. Kitheka, M. Saulo, D. Murage, The penetration level of auxiliary service voltage transformer substations on a power network for rural electrification.," in Kabarak University 5th Annual International Conference., July 2015.

[12] Jacobson D. A. N (2000) example of ferroresonance in high voltage power system proceedings of the 1999 international conference on power system transients.

[13] Namsil K, Lorenz P. (2008): Appropriate Distributed Generation Technology for Electrifying the village. Hague, Nertherlands.

[14] MNES (2002 -2003): Ministry of nonconventional energy Sources, INDIA.

[15] M. Globler, "Determination of transmission line parameters from time stamped data," masters thesis, university of Pretoria, July 2007.

[16] M. Saulo, C. Gaunt, penetration level of unconventional rural electrification technologies on power networks. PhD thesis, University of Capetown, May 2014. 